\title{
USO E COBERTURA DA TERRA NA FLORESTA NACIONAL DO JAMANXIM, NOVO PROGRESSO, PARÁ: CONSIDERAÇÕES SOBRE SUA DESAFETAÇÃO
}

\author{
Bianca Chaves Marcuartú ${ }^{1}$ \\ Andréa dos Santos Coelho ${ }^{2}$ \\ Rosana Quaresma Maneschy ${ }^{3}$ \\ Otávio do Canto ${ }^{4}$
}

\begin{abstract}
Resumo: $O$ artigo aborda o processo de desafetação sofrido pela Floresta Nacional do Jamanxim (Novo Progresso - PA), o qual distribuiu parte de sua extensão entre a nova Área de Proteção Ambiental do Jamanxim e o Parque Nacional do Rio Novo. Foram conduzidas análises temporais de desmatamento, cobertura e uso do solo nos limites antigos da Floresta Nacional em 2004 e 2008, e dentro dos novos limites para 2014. Apesar da diminuição no desmatamento após sua criação, em 2006, Jamanxim é a Floresta Nacional com maior área desmatada em toda a Amazônia. A classe Pasto representou a maior porcentagem encontrada dentro das áreas desmatadas, em todos os anos analisados, aumentando mesmo após 2006. Distribuindo-se o uso nas novas áreas, $68,5 \%$ da classe Pasto se encontrava na região destinada à Área de Proteção Ambiental. Esse resultado demonstra uma estratégia de apropriação de terras públicas como forma de pressão sobre unidades de conservação.
\end{abstract}

Palavras-chave: Ordenamento do Território; Unidades de Conservação; Flona Jamanxim; Serviços Ambientais.

\section{USE AND EARTH COVERAGE IN THE NATIONAL FOREST OF JAMANXIM, NEW PROGRESS, PARÁ: CONSIDERATIONS ABOUT ITS DISAFFECTION}

\begin{abstract}
The article addresses the reduction process suffered by the Jamanxim National Forest (Novo Progresso - PA), which distributed part of its extension between the new Jamanxim Environmental Protection Area and the Rio Novo National Park. It was conducted temporal analyzes of deforestation, land use and cover in the old limits of the National Forest in 2004 and 2008, and within the new limits for 2014. Despite the decrease in deforestation after its creation, in 2006, Jamanxim is the National Forest with the highest deforested area throughout the Amazon. The Pasture class represented the highest percentage found within the deforested areas, in all analyzed years, increasing even after 2006. In the new areas, $68.5 \%$ of the pasture class were located in the region designated for the

\footnotetext{
Núcleo de Meio Ambiente da Universidade Federal do Pará - NUMA/UFPA. E-mail: bianca_marcuartu@hotmail.com

2 Núcleo de Meio Ambiente da Universidade Federal do Pará - NUMA/UFPA. E-mail: andrea_geoambiente@hotmail.com

${ }^{3}$ Núcleo de Meio Ambiente da Universidade Federal do Pará - NUMAUFPA. E-mail: romaneschy@hotmail.com

${ }^{4}$ Núcleo de Meio Ambiente da Universidade Federal do Pará - NUMAUFPA. E-mail: docanto@ufpa.br

Estudos Geográficos, Rio Claro, 15(2): p-p, jul./dez. 2017 (ISSN 1678-698X)

http://www.periodicos.rc.biblioteca.unesp.br/index.php/estgeo
} 
Uso e cobertura da terra na Floresta...

Environmental Protection Area. This result demonstrates a strategy of public lands appropriation as a form of pressure on protected areas.

Keywords: Spatial Planning; Conservation Units; Jamanxim National Forest; Environmental Services.

\section{INTRODUÇÃO}

Ao se discutir as diversas problemáticas que envolvem o bioma amazônico pode-se considerar como uma das questões mais urgentes, a perda inexorável de funções essenciais fornecidas pelas florestas como consequência do avanço do desmatamento. Esse tópico envolve duas questões fundamentais: Quais as principais motivações para o desmatamento? E quais são as formas eficientes de contê-lo?

Uma ferramenta utilizada na manutenção da integridade dos ecossistemas e seus respectivos serviços ambientais são as Unidades de Conservação (UCs). Inspiradas em um conceito americano criado em 1872, elas se baseiam na identificação de áreas imprescindíveis para o fornecimento de benefícios à sociedade humana, como proteção de reservas de água, conservação dos solos e mitigação dos efeitos das mudanças climáticas. A partir dos anos 2000 , essas áreas foram padronizadas em um sistema unificado, o Serviço Nacional de Unidades de Conservação (SNUC), que prevê a existência de 12 categorias de UCs, dos grupos de proteção integral e de uso sustentável. Além disso, o Brasil também dispõe de um mapa de áreas prioritárias para a conservação da biodiversidade para embasar a criação de novas UCs, sendo o avanço do desmatamento um forte indutor para novas criações (FONSECA; LAMAS, KASECKER, 2010).

Apesar de ser um instrumento de ordenamento territorial, a implementação deste sistema enfrenta vários obstáculos, como falta de mão de obra e infraestrutura básica, além de ausência de estudos técnicos e regularização fundiária (MEDEIROS, YOUNG; PAVESE; ARAÚJO, 2011). A Administração Pública assume uma postura inconsistente e conflituosa com a premissa conservacionista, alterando limites e categorias de UCs conforme a depredação avança suas fronteiras. Entre 1995 e 2013, os poderes Executivo e Legislativo reduziram 2,9 milhões de hectares de UCs na Amazônia (MARTINS et al., 2014).

Esse é o caso da Floresta Nacional do Jamanxim (Flona Jamanxim), o ponto central de diversas disputas e conflitos, culminando na redução drástica de seus limites, por ação de uma Medida Provisória, para cerca de $43 \%$ de seu tamanho original, em dezembro de 2016. A Medida Provisória (MPV) 756/2016 foi aprovada sob a forma do Projeto de Lei de Conversão (PLV) 4/2017 no Senado em maio de 2017 e vetada pelo Presidente em junho, proibindo assim a re-edição da lei, e perdendo sua eficácia em decorrência do prazo. No entanto, o texto foi modificado e encaminhado para o Congresso Nacional, que avaliará a nova proposta de redução em apenas $27 \%$ de seus limites, e decidirá sobre o futuro da Flona.

Seu texto define que uma parte da área seja incorporada ao já existente Parque Nacional do Rio Novo (PARNA Rio Novo), enquanto que a região mais afetada pelo desmatamento seria incorporada a uma área externa recém-definida como Área de Proteção Ambiental Jamanxim (APA Jamanxim), uma categoria mais flexível de UC, por admitir a permanência de certas atividades produtivas não aceitas em uma Flona. No entanto, em maio de 2017, o texto original da MP foi 
editado por uma comissão mista de deputados e senadores, com adição de 12 emendas que preveem reduzir ainda mais o tamanho da Flona e da Apa, evidenciando a postura volátil do poder público em relação ao tema.

O presente artigo propõe realizar uma análise temporal da área original da Flona Jamanxim, antes (2004) e após sua criação em 2006 (2008 e 2014), observando os diversos usos encontrados na área, identificando assim quais deles são vetores no avanço do desmatamento, o que irá fornecer subs ídios para o debate a respeito dos limites e decisões sobre o futuro da área. A análise foi baseada em dados de uso e cobertura do solo do projeto TerraClass, uma realização do Instituto Nacional de Pesquisas Espaciais (INPE), em parceria com a Empresa de Pesquisas Agropecuárias (EMBRAPA), e dados oficiais dos limites da UC do Instituto Chico Mendes de Conservação da Biodiversidade (ICMBio).

Também foi feita a delimitação específica das áreas que vieram a ser desafetadas da Flona, para verificar a distribuição do uso da terra dentro de cada limite e onde se encontram os focos de desmatamento. Esses dados serão complementados com a reflexão a respeito dos fundamentos técnicos para redução desta Floresta e as possíveis consequências no fornecimento de serviços ambientais, na evolução do desflorestamento e no padrão de ocupação da região.

\section{A FLONA JAMANXIM NO CONTEXTO DE ORDENAMENTO TERRITORIAL DA ÁREA DE INFLUÊNCIA DA BR - 163}

Ao analisar unidades territoriais no contexto da configuração espacial da Amazônia, é necessário compreender o histórico da formação da região, em especial, a partir da década de 1970, ditado pelas políticas de ordenamento territorial, colonização dirigida e integração econômica da região ao restante do país. Esse processo foi marcado pelo conflito entre diferentes atores, visto que a principal motivação de ocupação do território foi o interesse na exploração de recursos naturais e uso do solo, o que se deu por meio de modelos insustentáveis de apropriação e uso.

Becker (1995) define três grandes períodos na história de ocupação amazônica: sua formação territorial (1616-1930), o planejamento regional e federalização do território (1930-1985) e o período atual, denominado de Fronteira Experimental. Os estudos de diagnóstico socioeconômico da BR-163 no âmbito do Zoneamento Ecológico-Econômico (VENTURIERI, 2008) mostram que desde as fases iniciais da colonização, nos séculos XV e XVI, é observada a transposição de fronteiras impulsionada pela busca por recursos, como as drogas-do-sertão, mantendo-se no ciclo da borracha, no século XIX.

A expansão do mercado de látex avançou ao longo dos rios, ocupando áreas originalmente habitadas por comunidades tradicionais, forçando a população indígena ao constante deslocamento para novas áreas, negando seu direito ao espaço, esgotando recursos e dispersando-os. O extrativismo da borracha também foi responsável por um intenso fluxo migratório de nordestinos para a Amazônia, com o intuito de suprir a necessidade de mão de obra.

A estagnação econômica, após o declínio da borracha, foi o escopo para grandes mudanças na estrutura espacial e econômica, antes baseada em produtos de origem nativa, pouca alteração dos ambientes naturais e de caráter adaptativo 
dando lugar a um novo padrão: as políticas de integração nacional. Idealizadas durante a ditadura militar, estas políticas incorporavam duas ideologias que caracterizaram esse governo: o forte sentimento nacionalista e os grandes projetos de desenvolvimento econômico. Os militares fundamentavam essa abordagem na necessidade de proteção territorial da Amazônia, com o lema "Integrar para não entregar", aliada ao potencial econômico que a região apresentava para atividades mineradoras, madeireiras e agropecuárias (VENTURIERI, 2008).

As estratégias de instalação das políticas foram denominadas de "malha programada" e envolviam a criação de infraestrutura de integração para intensificar o povoamento e fluxo de pessoas e mercadorias; criação de instituições, como o Banco da Amazônia (BASA) e a Superintendência para o Desenvolvimento da Amazônia (SUDAM); projetos hidrelétricos e minerais e projetos de colonização agrícola, como o Plano de Integração Nacional (PIN) e o Programa de Redistribuição de Terras e Estímulo à Agroindústria nas Regiões Norte e Nordeste (PROTERRA). O Programa de Integração Nacional tinha finalidade de financiar a construção de infraestrutura nas áreas de atuação da SUDAM, dentre elas, a rodovia Transamazônica (BR-020), no eixo leste-oeste; e a Cuiabá-Santarém (BR-163), na direção sul-norte, complementando o alcance da Belém-Brasília (BR-010) (ROCHA; CANTO, 2007).

A abertura de estradas é o ponto inicial no processo de desmatamento, pois permite a expansão humana e o alcance a recursos naturais antes inacessíveis. $O$ extrativismo de recursos converte-se em agricultura familiar e pastagens para a criação extensiva de gado, especialmente em grandes propriedades, sendo este fator responsável por cerca de $80 \%$ das florestas desmatadas na Amazônia Legal. A proporção do desmatamento em função da distância das estradas na Amazônia Legal tem, normalmente, padrões exponenciais, ou seja, grande proporção de desmatamento próximo às estradas (FERRE IRA; VENTICINQUE; ALMEIDA, 2005).

O período posterior à construção das BR-020 e BR-163 é caracterizado pela ruptura e redefinição da estrutura anterior e passa a se alicerçar na agropecuária, na colonização oficial e na interiorização do povoamento por meio de um sistema planejado e misto de ocupação do território, tendo no transporte rodoviário o principal eixo articulador da espacialidade regional. O processo de colonização do Instituto Nacional de Colonização e Reforma Agrária (INCRA), baseado na estrutura preexistente de cidades, como Altamira, Itaituba, Marabá e Santarém, induziu revigoramento e estimulou, como centros de polarização, o conjunto de novos núcleos urbanos (na "área de influência da BR-163"), planejados e espontâneos, emergentes do Plano Integrado de Colonização (PIC) e dos processos migratórios da região Sul e Sudeste para as bordas da Transamazônica e da Cuiabá-Santarém (VENTURIERI, 2008).

Segundo Castro, Monteiro, Castro (2002), especificamente em Novo Progresso e Castelo de Sonhos, o novo padrão de ocupação é representado pela chegada de pessoas na década de 1970, atraídas pela construção da BR-163 e pelos programas de integração, com um formato de lotes de 2.500 hectares. A pecuária e a pequena produção familiar, embora de forma reduzida, estavam presentes desde o final dos anos 1970. No entanto, é em torno da pecuária e da madeira que se desenvolve a economia atual da região, e que se definem as formas de apropriação da terra. 
Castro, Monteiro, Castro (2004) relatam que naquela ocasião, o movimento mais expressivo em torno da BR-163 era a pecuarização, embora em áreas ainda pequenas quando comparadas as de floresta, no município de Novo Progresso até a fronteira com o Mato Grosso. Contudo, o pecuarista tinha como estratégia explícita a expansão de sua propriedade pela adição de novas terras pela grilagem, uma prática comum e incontrolável pela ausência ou conivência do Estado. Essa demanda permanente por novas terras incentiva o abandono dos lotes antigos pelos colonos.

Com o progressivo agravamento do desmatamento e ocupações ilegais, o Governo Federal lançou em 2004, o Plano de Desenvolvimento Regional Sustentável para a Área de Influência da Rodovia BR-163, para atuar na redução dos impactos socioambientais provocados pelo asfaltamento da rodovia, por meio de diversas ações. Em fevereiro de 2005 foram decretados 8,2 milhões de hectares sob Área sob Limitação Administrativa Provisória (ALAP), uma medida cautelar para conter o desmatamento, enquanto são tomadas providências definitivas a respeito da destinação da área.

Por conseguinte, em 2005, o Ministério do Meio Ambiente e o da Integração Nacional iniciaram a elaboração da política do Zoneamento Ecológico-Econômico da BR-163, executado pela Empresa Brasileira de Pesquisa Agropecuária (EMBRAPA), publicado em 2008. Posto que um dos objetivos do ZEE é dotar o governo de bases técnicas para decidir a melhor forma de uso e ordenação do território, a palavra final sobre as restrições de certos usos da terra caberia ao governo ou à Assembleia Legislativa, mediante a elaboração de leis (BENATTI, 2004).

A delimitação como ALAP na BR-163 permitiu a criação de um mosaico de Unidades de Conservação em 2006 para conter o processo de ocupação desordenado e predatório e permitir a preservação da floresta concomitante a sua exploração em bases sustentáveis. A área do mosaico que está localizada na Região de Integração do Tapajós está representada no mapa 1, distinguindo aquelas criadas em 2006, das preexistentes. 
Mapa 1 - Mosaico de Unidades de Conservação da Área de Influência da BR - 163

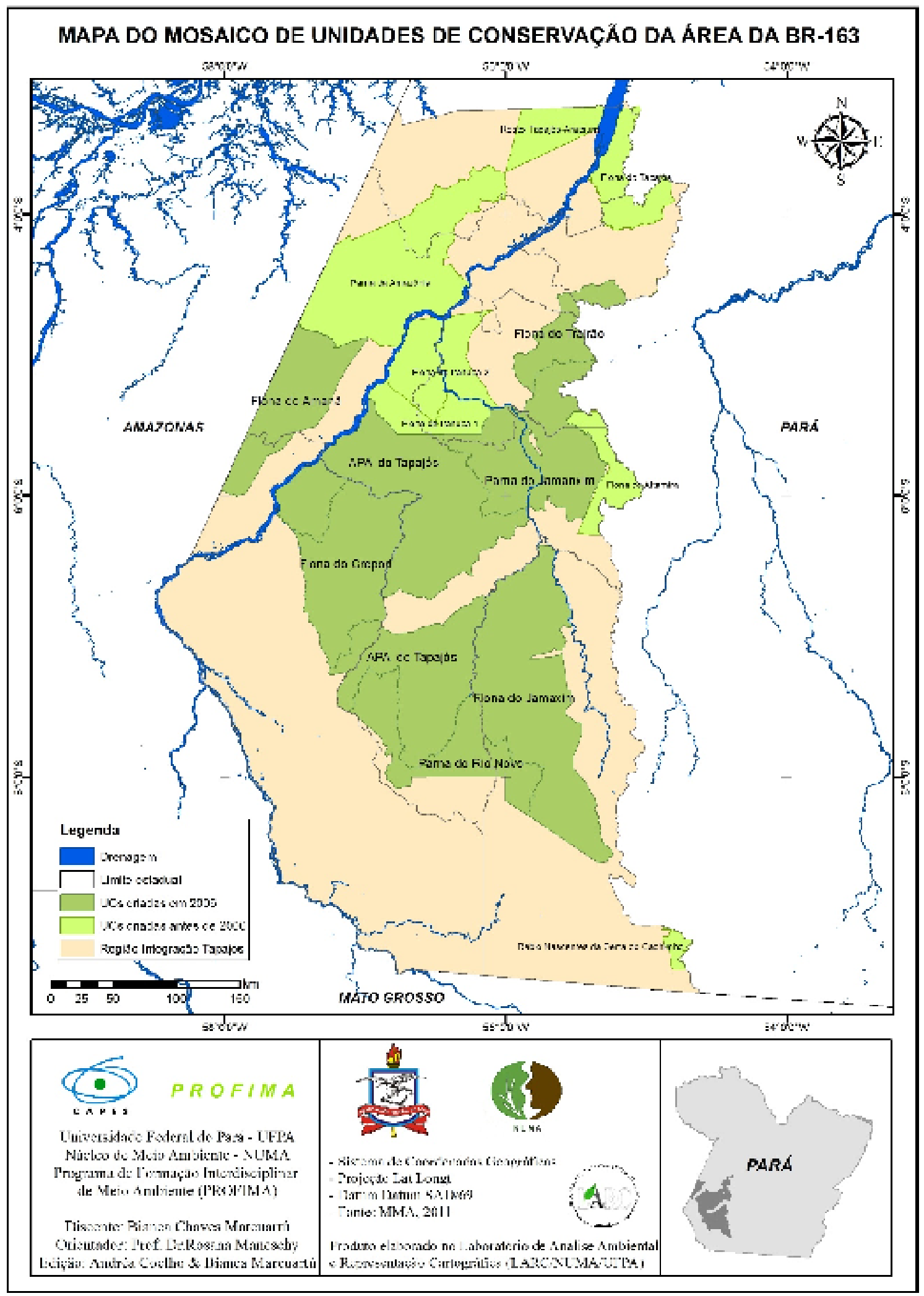

Fonte: Coelho; Marcuartú, 2017

Conforme o histórico conflituoso de ocupação da área, a criação desse mosaico de UCs gerou grande polêmica entre os atores sociais envolvidos, 
associada primeiramente à tensão fundiária, à disputa pela terra, à grilagem e aos possíveis efeitos sobre o desmatamento. Esse fenômeno foi notável no município de Novo Progresso, onde foram implantadas a Flona Jamanxim e o Parna Jamanxim, devido a sua grande taxa de ocupação, por ser cortado pela BR-163 e receber um grande contingente populacional decorrente do avanço da fronteira agropecuária sobre a região (VENTURIERI, 2008).

Os critérios utilizados para a definição dos limites da Flona foram questionados, alegando-se que não contemplavam a proposta apresentada em Audiência Pública antes da sua criação, em que a área da Flona ocuparia $46 \%$ do total previsto, pela criação e modificação de categorias, com base, principalmente, na configuração topográfica e no grau de ocupação da região (BRAS IL, 2009).

A instabilidade política do país e grandes mudanças ministeriais levaram a uma evolução desse quadro em 2016, impulsionando políticos locais a se unirem a fazendeiros e grupos oligárquicos da região para pressionar o Congresso Nacional, levando à desafetação da área em dezembro do mesmo ano. Dos $13.015,55 \mathrm{~km}^{2}$ originais, $7.421,67 \mathrm{~km}^{2}$ foram desafetados, sendo uma parte destinada à ampliação do Parna Rio Novo (59\%) e outra à recém-criada APA Jamanxim (41\%), deixando a Flona com apenas $5.593,88 \mathrm{~km}^{2}$ remanescentes. Além da área desafetada da Flona, a nova APA Jamanxim também é composta de uma área externa às margens da BR-163, onde não existia nenhum tipo de UC anteriormente, essas mudanças são ilustradas no mapa 2.

O argumento dos parlamentares para aprovação da mudança é a necessidade de associar o desenvolvimento econômico da região com a exploração da floresta. No entanto, diversas entidades governamentais e não governamentais foram contrárias à desafetação, por substituir o fortalecimento da fiscalização e manutenção das UCs por medidas paliativas que comprometem a integridade da Flona. Essa postura inconsistente e descomprometida, cede às pressões para mudanças de regras e enfraquece a credibilidade da política de conservação e do próprio SNUC. Araújo, Barreto, Baima, Gomes (2017) observam que o Governo Federal e governos estaduais têm optado pela desafetação das UCs ocupadas ao invés da remoção e indenização dos posseiros e que, se cederem a todas as pressões, o Brasil perderá, pelo menos, 10 milhões de hectares de áreas protegidas.

Martins et al. (2014), ao avaliarem dez áreas protegidas na Amazônia ${ }^{5}$, cinco anos após desafetações, apontam um aumento de cerca de $50 \%$ na taxa de desmatamento nas áreas que perderam status de UC ou têm seu grau de proteção reduzido, em comparação com o mesmo período antes da alteração, pois beneficiam ocupantes irregulares e estimulam novas invasões e desmatamento. As principais justificativas para essas medidas são a necessidade de regularização fundiária e a instalação de Usinas Hidrelétricas, responsáveis por, respectivamente, $74 \%$ e $42 \%$ dos casos.

No caso das mudanças ocorridas na Flona Jamanxim, o ponto crítico é a área anexada à nova APA. Essa é a categoria mais branda dentre as unidades de uso sustentável, onde é permitida uma gama maior de atividades humanas, como a mineração e a indústria, e onde se incluem até mesmo núcleos urbanos.

\footnotetext{
5 Terra Indígena Baú, Terra Indígena Apyterewa, Floresta Nacional Bom Futuro, Floresta Estadual de Rendimento Sustentável Rio Madeira, Parque Estadual do Xingu, Estação Ecológica Rio Ronuro, Estação Ecológica Antônio Mugica Nava, Estação Ecológica Serra dos Três Irmãos, Reserva Extrativista Jaci-Paraná e Parque Estadual do Araguaia.
}

Estudos Geográficos, Rio Claro, 15(2): p-p, jul./dez. 2017 (ISSN 1678-698X)

http://www.periodicos.rc.biblioteca.unesp.br/index.php/estgeo 
Frequentemente, essas áreas não cumprem o mínimo necessário para alcançar os objetivos de conservação a que se destinam. São poucos os exemplos de APAs em que realmente existem planejamento e manejo compatíveis ao uso e à conservação dos recursos naturais (FONSECA; LAMAS; KASECKER, 2010). Em análise do desmatamento em UCs, Araújo, Barreto, Baima, Gomes (2017) constataram que dentre as categorias de uso sustentável, as que mais sofrem desmatamento são as APAs, com 42,4\%; a Floresta Nacional/ Estadual (FLONA/FLOTA), com 21,1\%; e a Reserva Extrativista (RESEX), com 16,6\%.

A APA tem o objetivo básico de proteger a diversidade biológica, além de disciplinar o processo de ocupação e assegurar a sustentabilidade do uso dos recursos naturais e é constituída por terras públicas ou privadas. A mudança desses $3.047 \mathrm{~km}^{2}$ de Flona para Apa permite a permanência das grandes propriedades privadas que existiam ilegalmente na área, ao invés da desapropriação prevista pelo SNUC, regularizando a situação fundiária e ambiental daqueles que agiam em desacordo com a lei. 
Mapa 2 - Alteração dos limites da FLONA Jamanxim

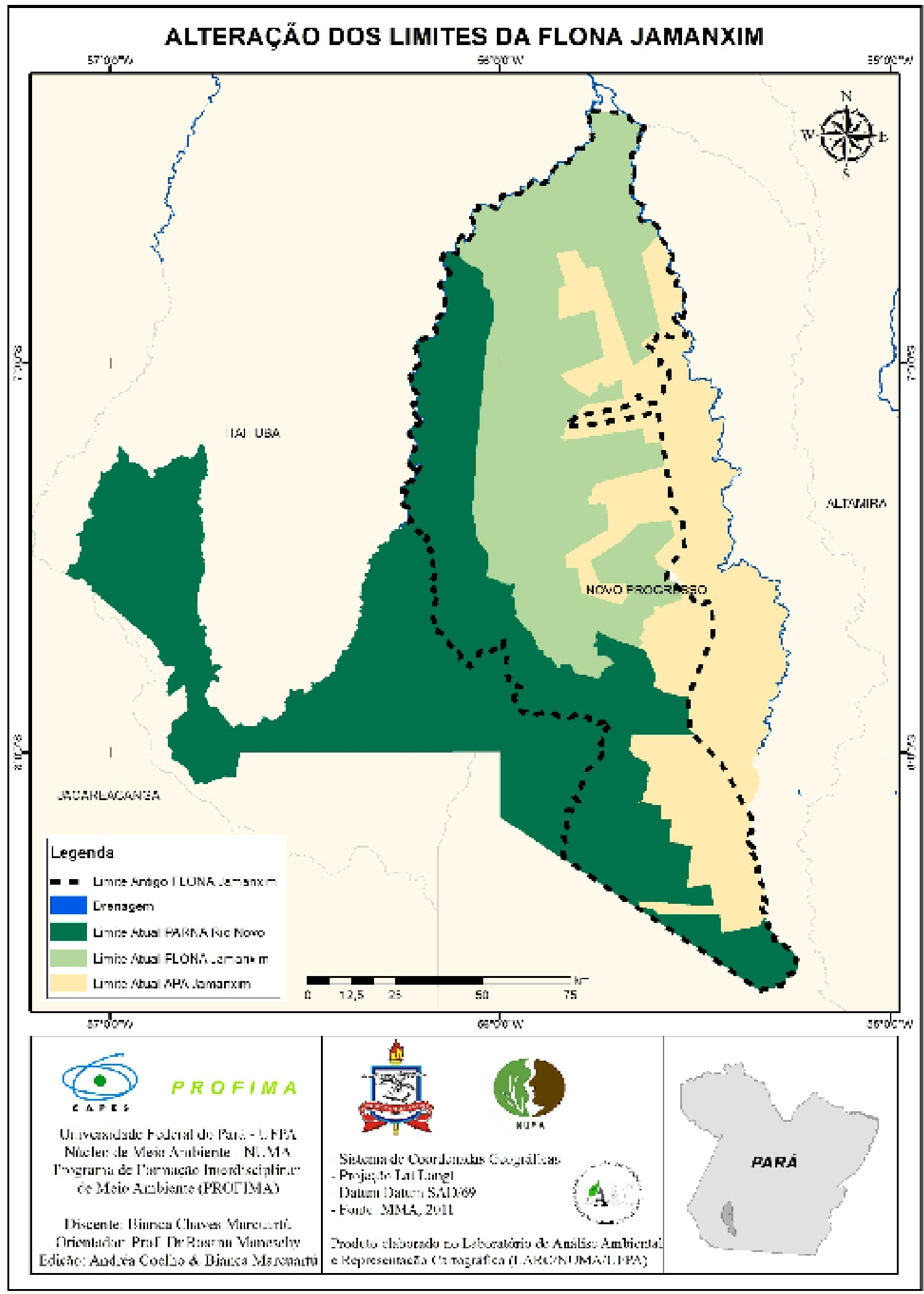

Fonte: Coelho; Marcuartú, 2017

Estudos Geográficos, Rio Claro, 15(2): p-p, jul./dez. 2017 (ISSN 1678-698X)

http://www.periodicos.rc.biblioteca.unesp.br/index.php/estgeo 


\section{UNIDADES DE CONSERVAÇÃO NA CONTENÇÃO DO DESMATAMENTO E FORNECIMENTO DE SERVIÇOS AMBIENTAIS}

A criação de Unidades de Conservação e Áreas Protegidas é uma forma de intervenção governamental para ordenamento territorial, que leva em consideração aspectos da realidade ambiental local como histórico da região, pressão antrópica e importância biológica, cultural ou de beleza cênica. Essas áreas têm seu uso e ocupação restringidos com o objetivo de conservação da biodiversidade, manutenção dos serviços ambientais e proteção das populações locais.

No Brasil, essas áreas são divididas entre unidades de proteção integral e de uso sustentável. O grupo das unidades de proteção integral visa à conservação da biodiversidade, e inclui as categorias Estação Ecológica, Reserva Biológica, Parque Nacional, Monumento Natural e Refúgio de Vida Silvestre. Essas categorias de manejo destinam-se à preservação integral da biota e demais atributos naturais em seus limites, permitindo a pesquisa científica e visitação pública, sempre sujeitas à regulação. As unidades de uso sustentável visam compatibilizar a conservação da natureza com o uso sustentável de seus recursos naturais, sendo distribuídas entre as categorias de manejo Área de Proteção Ambiental, Área de Relevante Interesse Ecológico, Floresta Nacional, Reserva Extrativista, Reserva de Fauna e Reserva de Desenvolvimento Sustentável (BRASIL, 2002).

A necessidade e importância de áreas protegidas é totalmente justificada em um país megadiverso como o Brasil, e com propósitos concretos de conservação de biodiversidade e recursos, no entanto, como instrumento de política pública para contenção do desmatamento e preservação de biomas, elas são realmente efetivas? Ferreira, Venticique, Almeida (2005) buscaram demostrar essa questão pela análise de distribuição proporcional do desmatamento dentro e fora das Unidades de Conservação e Terras Indígenas, nos estados de Mato Grosso, Rondônia e Pará, entre 2001 e 2003. Os resultados mostraram que o desmatamento foi cerca de dez a vinte vezes menor dentro das Unidades de Conservação e Terras Indígenas do que em áreas externas, demonstrando a importância dessas áreas para diminuir o processo do desmatamento nos três estados.

De Fries et al. (2005) analisaram, entre 1981 e 2001, a cobertura florestal de uma amostra de 198 áreas protegidas de biomas de florestas tropicais, incluindo áreas brasileiras. Os resultados apontaram que, em 2001, as áreas protegidas de florestas úmidas na América Latina, incluindo as da Mata Atlântica e Amazônia, apresentavam aproximadamente $90 \%$ de cobertura florestal.

Martini et al. (2012) também corroboram os resultados anteriores ao verificar a dinâmica do uso e cobertura da terra no Parque Estadual Monte Alegre (PEMA) no munic ípio de Monte Alegre (PA), no entanto, frisam que apesar da criação da UC ter reduzido a taxa de desmatamento, ainda há a ocorrência de fatores que ameaçam a integridade biológica da área, o que revela a necessidade de adotar ações de controle diferenciadas para assim permitir que estas unidades cumpram seu papel funcional de forma plena.

Dessa forma, infere-se que a simples delimitação de uma área como unidade de conservação não é suficiente como política pública consistente. Vallejo (2002) indica que, ao estabelecer o controle do homem sobre o próprio homem para proteção da natureza, uma questão fundamental a ser considerada é a agregação 
de "valor" ao espaço e, por conseguinte, aos recursos espaciais. A relação sociedade-espaço é uma relação valor-espaço, pois é determinada pelo trabalho humano. Por isso, a apropriação de recursos do próprio espaço, a construção de formas humanizadas sobre ele, a conservação de seus atributos naturais e culturais, tudo isso representa criação de valor.

Mesmo áreas sob regime de preservação integral e teoricamente intocadas, podem representar estratégias para valorização futura, por meio da atribuição de valores aos bens naturais conservados, que geram benefícios para a sociedade presente e para as próximas gerações. A Economia Ecológica divide esses valores em: Valores Econômicos Diretos, produtos que são diretamente colhidos e usados pelas pessoas; e Valores Econômicos Indiretos, que estão associados a processos ambientais e serviços proporcionados por ecossistemas que geram benefícios econômicos sem que haja qualquer forma de exploração econômica direta, mas podem ser cruciais para a disponibilidade de recursos dos quais as economias dependem (VALLEJO, 2009).

Nesse âmbito, foram desenvolvidas várias abordagens para atribuir valores econômicos à variabilidade genética, às espécies, às comunidades e aos ecossistemas. Medeiros, Young, Pavese, Araújo (2011) analisaram o impacto e o potencial econômico de alguns dos múltiplos bens e serviços provisionados pelas unidades de conservação, dentre eles a redução na emissão de carbono em, pelo menos, 2,8 bilhões de toneladas, com um valor estimado em $\mathrm{R} \$ 96$ bilhões; geração de $\mathrm{R} \$ 16,5$ milhões anuais na produção de borracha em reservas extrativistas; contribuição estimada entre $\mathrm{R} \$ 459,3$ e 519,2 milhões anuais por meio do turismo em parques com cobrança de ingresso.

Os autores também tratam dos benefícios fornecidos em relação ao uso da água, como a participação em $80 \%$ da hidroeletricidade do país, vinda de fontes geradoras com, pelo menos, um tributário a jusante de unidade de conservação; $9 \%$ da água para consumo humano diretamente captada em unidades de conservação e $26 \%$ em fontes a jusante de unidade de conservação. Ainda, em bacias hidrográficas e mananciais, a maior cobertura florestal faz com que o custo associado ao tratamento da água destinada ao abastecimento público seja sensivelmente reduzido.

As áreas protegidas são um componente essencial na implantação de medidas para Redução de Emissões Decorrentes do Desmatamento e da Degradação de Florestas (REDD) e consequente mitigação das mudanças climáticas, tendo em vista seu potencial para evitar a emissão para a atmosfera, de grande parte do Carbono armazenado na Floresta Amazônica brasileira. SoaresFilho et al. (2010) analisando o efeito de cada uma das 595 áreas protegidas na Amazônia brasileira, incluindo Unidades de Conservação, Terras Indígenas e Áreas Militares, concluiu que elas, se totalmente implementadas, tem o potencial de evitar a emissão de $8.0 \pm 2.8 \mathrm{Pg}$ de Carbono até 2050. Esses valores podem funcionar como premissa de um possível acordo climático internacional que inclua incentivo econômico para países tropicais que reduzam suas emissões por desmatamento.

Com a demonstração da eficiência na estratégia de implementação de áreas protegidas, compreende-se sua necessidade em áreas com histórico de uso predatório, especialmente quando possuem grande relevância ecológica, como o caso da área de influência da BR-163, para proteção do patrimônio natural genético da biodiversidade de parte da Floresta Amazônica brasileira, com o desenvolvimento 
de pesquisas científicas e implementação de políticas voltadas ao uso sustentável e a conservação dos recursos naturais.

\section{METODOLOGIA}

As discussões sobre a alteração nos limites da Flona Jamanxim se fundamentaram em alguns parâmetros quantitativos a respeito da perda de floresta primária em função do uso e cobertura do solo, confrontando-os com informações qualitativas do Plano de Manejo da Floresta Nacional do Jamanxim (PMFNJ) e Estudo Técnico de Revisão dos Limites, realizado em 2009 diante da possível desafetação da área. Os dados de desmatamento são provenientes do projeto Monitoramento da Floresta Amazônica Brasileira por Satélite (PRODES) realizado pelo Instituto Nacional de Pesquisas Espaciais (INPE), que realiza o monitoramento do desmatamento por corte raso na Amazônia Legal, por meio de imagens de satélite Landsat 5, CBERS 2 e 2B e Resourcesat 1, com área mínima de 6,25 hectares.

Considerando que a ocupação da terra é a principal fonte de conflito em relação aos limites da Flona, também foi realizada uma análise temporal do uso da terra a partir dos seus limites originais, iniciando com o ano de 2004, antes da sua criação, seguindo com 2008 e 2014, como forma de adicionar subs ídios ao debate a respeito da redução ocorrida em 2016. Para isso, foram elaborados mapas temáticos utilizando dados vetoriais do projeto TerraClass, o qual classifica os padrões de uso e cobertura da terra na Amazônia Legal, realizados pelo INPE em parceria com a EMBRAPA. O mapeamento é feito dentro de áreas consideradas como desmatamento pelo PRODES, utilizando imagens Landsat-5, Liss e DMC, com uma frequência bianual.

A escolha dos anos se deu em função da disponibilidade de dados do projeto e, também, para demonstrar um cenário representativo do estado da área, ao se considerar um período anterior à criação da Flona; um segundo, logo após sua criação, e por fim, um terceiro momento mais recente e próximo ao implemento da sua desafetação. Definidos os anos, os dados foram intersectados para a região da Flona Jamanxim, utilizando o limite oficial antigo proveniente do ICMBio, e foram realizados cálculos de área para sistematização dos dados em tabelas, utilizando o software SIG ArcGis.

O projeto TerraClass é publicado com 15 classes, porém por critérios de escala de apresentação, representatividade na área e melhor compreensão dos dados, foram usadas apenas 9 classes nas análises realizadas nesse artigo, representadas na tabela 1. No caso das classes Agricultura Anual, Área Urbana e Mosaico de Ocupação, simplesmente não foram encontradas dentro da área, devido à não ocorrência dessa atividade, ou ocorrência em área inferior à mínima mapeada. 
Tabela 1 - Esquematização das Classes de Uso e Cobertura

\begin{tabular}{|c|c|c|}
\hline Classes PRODES & Classes Terraclass & Classes usadas na análise \\
\hline Floresta & Floresta & Floresta \\
\hline Não Floresta & Não Floresta & Não Floresta \\
\hline Hidrografia & Hidrografia & Hidrografia \\
\hline Área Não Observada & Área Não Observada & Área Não Observada \\
\hline \multirow{11}{*}{$\begin{array}{l}\text { Desflorestamento } \\
\text { Acumulado }\end{array}$} & Agricultura Anual & - \\
\hline & Área Urbana & - \\
\hline & Mineração & Mineração \\
\hline & Mosaico de Ocupação & - \\
\hline & Outros & Outros \\
\hline & Pasto com Solo Exposto & \multirow{4}{*}{ Pasto } \\
\hline & Pasto Limpo & \\
\hline & Pasto Sujo & \\
\hline & Regeneração com Pasto & \\
\hline & Vegetação Secundária & Vegetação Secundária \\
\hline & Desmatamento do Ano & Desmatamento do Ano \\
\hline
\end{tabular}

A classe Desmatamento do Ano, também referida como Incremento, existe devido à diferença de periodicidade de TerraClass (bianual) e PRODES (anual), tendo assim um dado de desmatamento que ocorre entre períodos de mapeamento do uso do solo, que não é simplesmente incluído na classe de Desmatamento Acumulado, para manter uma caracterização mais acurada da dinâmica de uso e avanço do desmatamento. Dessa forma, o Desflorestamento do Ano deve ser entendido como novas áreas desmatadas no período citado (2004, 2008 ou 2014), enquanto que o Desmatamento Acumulado será o montante das classes Pasto, Mineração, Vegetação Secundária e Desmatamento do Ano, visto que são as únicas classes encontradas na área mapeada oriundas de corte raso, enquanto que as demais são de cobertura, ou seja, se referem a estruturas naturais (Floresta, Hidrografia, Não Floresta e Outros) ou Áreas Não Observadas devido à cobertura de nuvens.

\section{RESULTADOS E DISCUSSÃO}

Assim, para a realização das análises propostas por este trabalho, a primeira informação extraída da base de dados do PRODES se refere às Florestas Nacionais com maior área desmatada em toda a Amazônia Legal (Tabela 2), em que a Flona do Jamanxim aparece em primeiro lugar, com 1.425,09 $\mathrm{km}^{2}$ desmatados. Esses dados corroboram os resultados de Araújo, Barreto, Baima, Gomes (2017), em análise do desmatamento em UCs na Amazônia Legal entre 2012 e 2015, em que a Estudos Geográficos, Rio Claro, 15(2): p-p, jul./dez. 2017 (ISSN 1678-698X) 
Jamanxim aparece como a mais desmatada dentre todas as unidades federais, e em terceiro lugar, quando consideradas todas as categorias.

Tabela 2 - Flonas da Amazônia Legal com maior área desmatada até 2014

\begin{tabular}{l|l|l|l|l}
\hline \multicolumn{1}{c|}{ NOME } & $\begin{array}{c}\text { ANO DE } \\
\text { CRIAÇÃO }\end{array}$ & $\begin{array}{c}\text { ÁREA } \\
\left(\text { KM }^{2}\right)\end{array}$ & $\begin{array}{c}\text { TOTAL } \\
\text { DESMATADO } \\
\text { KM }^{2} /(\%)\end{array}$ \\
\hline $\mathbf{1}$ & Floresta Nacional do Jamanxim & 2006 & $13.021,9$ & $1.425,09(11,0 \%)$ \\
$\mathbf{2}$ & Floresta Nacional Bom Futuro & 1988 & $2.783,2$ & $1.010,5(36,5 \%)$ \\
$\mathbf{3}$ & Floresta Nacional Tapajós & 1974 & $5.491,6$ & $354,08(6,5 \%)$ \\
$\mathbf{4}$ & Floresta Nacional do Itacaiúnas & 1998 & 817,9 & $350,7(42,9 \%)$ \\
$\mathbf{5}$ & Floresta Nacional de Roraima & 1989 & $44.879,2$ & $290,11(0,7 \%)$ \\
$\mathbf{6}$ & Floresta Nacional Altamira & 1998 & $7.609,5$ & $278,19(3,7 \%)$ \\
$\mathbf{7}$ & Floresta Nacional Saracá-Taquera & 1989 & $4.417,6$ & $169,24(3,9 \%)$ \\
$\mathbf{8}$ & Floresta Nacional Tefé & 1989 & $8.828,1$ & $113,89(1,3 \%)$ \\
$\mathbf{9}$ & Floresta Nacional do lquiri & 2008 & $15.056,8$ & $99,64(0,7 \%)$ \\
$\mathbf{1 0}$ & Floresta Nacional Jamari & 1984 & $2.248,1$ & $79,39(3,6 \%)$ \\
\hline
\end{tabular}

Fonte: Brasil (2014)

A colocação da Jamanxim poderia ser questionada, visto que ela possui a segunda maior área total nessa lista e, por consequência, teria uma maior extensão de desmatamento, mas não necessariamente proporção. No entanto, a tabela 2 também apresenta o resultado em porcentagem, o que permite verificar que a Jamanxim também está entre as primeiras, quando considerado o desmatamento proporcional, com perda de $11 \%$ de sua área de floresta original, sendo superada apenas pela Flona do Itacai únas (42,9\%) e Bom Futuro (36,5\%).

De acordo com seu decreto de criação, a Flona Jamanxim tinha por objetivos básicos promover o manejo de uso múltiplo sustentável dos recursos florestais, a manutenção e a proteção dos recursos hídricos e da biodiversidade, bem como o apoio ao desenvolvimento de métodos de exploração sustentável dos recursos naturais. Esse objetivo seria atingido pela contenção do desmatamento decorrente da criação de uma Flona, categoria de UC que limita a permanência e o uso da área às populações tradicionais que a habitem quando de sua criação, em conformidade com o disposto em regulamento e no Plano de Manejo da unidade (BRASIL, 2006).

No entanto, ao observar a evolução do desmatamento nesta Flona (Tabela 3) nota-se que o incremento no desmatamento prosseguiu, mesmo após sua criação em 2006, sendo que em alguns anos, essa taxa foi até maior que a observada antes da sua implantação (2007 e 2009). Esse aumento não é justificado pela presença de comunidades tradicionais, pois os incrementos após 2006 são demasiado extensos para corresponder à capacidade produtiva, geralmente com base na agricultura familiar, e padrão técnico utilizado por essas populações (BRASIL, 2002). 
Tabela 3 - Incremento no desmatamento na Flona Jamanxim

\begin{tabular}{|c|c|c|}
\hline Ano & $k m^{2}$ & $\%$ \\
\hline Acumulado até 1997 & 147,49 & $1 \%$ \\
\hline Incremento 2000 & 44,15 & $0,34 \%$ \\
\hline Incremento 2001 & 37,06 & $0,29 \%$ \\
\hline Incremento 2002 & 156,43 & $1,21 \%$ \\
\hline Incremento 2003 & 82,67 & $0,64 \%$ \\
\hline Incremento 2004 & 310,55 & $2,40 \%$ \\
\hline Incremento 2005 & 87,01 & $0,67 \%$ \\
\hline Incremento 2006 & 73,61 & $0,57 \%$ \\
\hline Incremento 2007 & 140,08 & $1,08 \%$ \\
\hline Incremento 2008 & 73,70 & $0,57 \%$ \\
\hline Incremento 2009 & 103,11 & $0,80 \%$ \\
\hline Incremento 2010 & 11,80 & $0,09 \%$ \\
\hline Incremento 2011 & 12,94 & $0,10 \%$ \\
\hline Incremento 2012 & 30,72 & $0,24 \%$ \\
\hline Incremento 2013 & 64,44 & $0,50 \%$ \\
\hline Incremento 2014 & 49,32 & $0,38 \%$ \\
\hline Total Desmatado até 2014 & $1.425,1$ & $11 \%$ \\
\hline Área Total Flona & $13.021,9$ & $100 \%$ \\
\hline
\end{tabular}

O próprio PMFJ (BRASIL, 2010) afirma que a área média dos estabelecimentos rurais é de 1.772 hectares, muito superior aos 300 hectares, equivalentes a quatro módulos fiscais no município de Novo Progresso, definidos pela Política Nacional da Agricultura Familiar e Empreendimentos Familiares Rurais como área máxima para ser categorizado como familiar.

Outro requisito da política é que o estabelecimento utilize, predominantemente, mão de obra da própria família nas atividades econômicas, o que não é observado na Flona, tendo apenas $14 \%$ dos empregados de cada unidade com relação de parentesco com o chefe do domicílio. Por meio de entrevistas descreve-se que $55 \%$ a $65 \%$ da área era ocupada por empreendimentos com proprietários moradores e residentes fora da Flona, provenientes da região Centro-Sul do Brasil, com um administrador local residindo em Novo Progresso ou Castelo dos Sonhos, e apenas um caseiro vivendo na propriedade. Entre 30 e 40 áreas eram, de fato, habitadas por uma família, o que corresponde a menos de $4 \%$ do total (BRASIL, 2009).

A presença de estabelecimentos não familiares e ocupação por comunidades não tradicionais revela a ocorrência de usos conflitantes e ilegais dentro dos limites da Flona Jamanxim. É uma situação esperada, considerando a forte insatisfação de atores locais com a criação da Flona e a própria questão de conflitos Estudos Geográficos, Rio Claro, 15(2): p-p, jul./dez. 2017 (ISSN 1678-698X) 
socioambientais que permeia toda a história de ocupação da Amazônia. Do Canto (2012) afirma que os conflitos socioambientais são decorrentes dos embates entre diferentes atores e grupos sociais que disputam a apropriação e uso dos recursos, sendo que na Amazônia ocorrem conflitos de múltiplas formas, decorrentes do controle e uso de diversos "recursos naturais".

Complementarmente, Souza (2014) afirma que a gestão de áreas protegidas, principalmente, as áreas de uso sustentável, enfrentam enormes problemas devido aos conflitos de interesses em torno da apropriação dos recursos, gerando conflitos ambientais de diversas magnitudes. Nas entre vistas sobre a visão das comunidades sobre a Floresta Nacional, o PMFNJ (BRAS L, 2010) revelou que os atores temem a possibilidade de serem obrigados a deixar a região e perderem todo o investimento efetuado ao longo de décadas de ocupação, como a elaboração de projetos de manejo florestal, que foram suspensos após a criação da Flona.

O Relatório para Revisão dos Limites da Flona (BRASIL, 2009) menciona que esses conflitos envolvem principalmente fazendeiros que haviam se apossado, ou comprado terras de terceiros e grileiros, geralmente, sem documentação legal e que mantinham enormes pretensões fundiárias na área que se tornaria a Flona Jamanxim. Esses foram os principais responsáveis pela articulação com políticos locais para mover uma ação na Justiça Federal para sustação dos efeitos do decreto de criação da Flona.

Os dados gerados a partir do mapeamento com imagem de 2004 (Tabela 4 e Mapa 3), demonstram a predominância da classe Pasto $\left(284,61 \mathrm{~km}^{2}\right)$ sob a área, antes da existência da Flona, representada por polígonos de grandes extensões. Além dessa dominância ser mantida nos anos 2008 e 2014, suas áreas aumentaram progressivamente, em taxas hiperbólicas $\left(787,92\right.$ e $\left.922,56 \mathrm{~km}^{2}\right)$, enfatizando a importância da atividade na área, o que envolve grande interesse na sua permanência. Dentre os impactos causados por essa atividade, o PMFNJ (BRASIL, 2010) cita a construção de ramais dentro das propriedades, que muitas vezes intersecta pontos de drenagem, provocando estagnação do fluxo fluvial, desconstituindo o ambiente aquático original e a vegetação circundante. Ademais, a utilização de fogo, um impacto atuante na unidade de conservação, representa tanto os efeitos da supressão do ambiente, como atinge negativamente os ambientes do entorno, pois passa a ser emissora de gases do efeito estufa e modificadora do microclima regional.

TABELA 4 - Uso e cobertura do solo nos limites antigos da Flona Jamanxim

\begin{tabular}{ll|l|l|l}
\hline Classes & $2004\left(\mathrm{~km}^{2}\right)$ & $2008\left(\mathrm{~km}^{2}\right)$ & $2014\left(\mathrm{~km}^{2}\right)$ \\
\hline Área Não Observada & 20,24 & 4,79 & 81,18 \\
Desflorestamento do & 315,50 & 74,24 & 49,23 \\
Ano & & & \\
Floresta & $12.211,62$ & $11.797,73$ & $11.522,62$ \\
Hidrografia & 4,76 & 4,76 & 4,76 \\
Mineração & 1,48 & 0,84 & 1,88 \\
Não Floresta & 61,00 & 61,00 & 61,00 \\
Outros & 6,24 & 1,29 & 2,01 \\
Pasto & 284,61 & 787,92 & 922,56 \\
Vegetação Secundária & 110,09 & 282,97 & 370,30 \\
\hline
\end{tabular}

Estudos Geográficos, Rio Claro, 15(2): p-p, ju 1./dez. 2017 (ISSN 1678-698X)

http://www.periodicos.rc.biblioteca.unesp.br/index.php/estgeo 


\begin{tabular}{l|l|l|l}
\hline Total & $13.015,55$ & $13.015,55$ & $13.015,55$ \\
\hline \multicolumn{4}{|c}{ Fonte: Marcuartú, 2017}
\end{tabular}

Mapa 3 - Análise Temporal do Uso e Cobertura do Solo no limite antigo da FLONA Jamanxim para os anos 2004/2008/2014

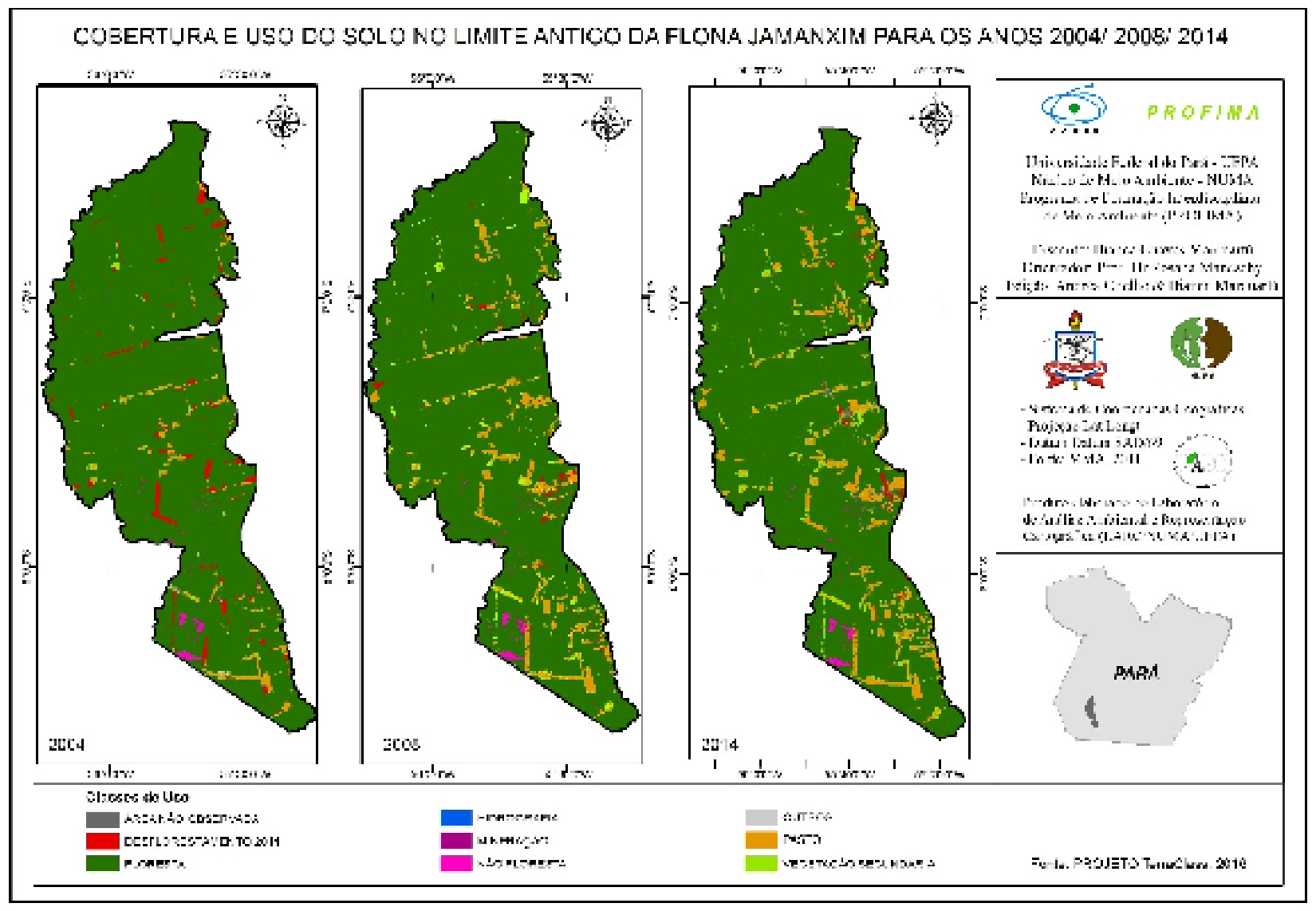

Fonte: Coelho; Marcuartú, 2017

Em relação à Mineração, observou-se uma grande diminuição inicial nas áreas após a criação da Flona, seguida de um aumento maior que o observado antes da criação $\left(1,48 ; 0,84 ; 1,88 \mathrm{~km}^{2}\right)$. Esse resultado corrobora com o encontrado no Plano de Manejo da Floresta Nacional do Jamanxim (BRASIL, 2010), em que foram identificados apenas 51 domicílios/barracos nos garimpos, mostrando um declínio, com a sobreposição de aberturas para agropecuária e consolidação de posses para garantir alguma margem de negociação com projetos e programas de governo para a região.

Apesar da extensão reduzida da área de Mineração comparada às de Pasto, os impactos observados resultantes dessa atividade são mais intensos. O processo de recomposição natural da vegetação nesses locais é bastante lento, uma vez que horizontes de solo férteis foram retirados, impossibilitando a regeneração natural da vegetação e, portanto, perpetuando os impactos de modificação da paisagem e, mais importante, o carreamento de sedimentos para o interior de drenagens próximas. Há também alteração nos aspectos qualitativos e regime hidrológico dos cursos de água e desencadeamento de processos erosivos (BRASIL, 2010).

Ao realizar a divisão do uso do solo entre as três áreas, para o ano de 2014 , foi possível correlacionar a proporção do desmatamento e de atividades 
propagadoras nas regiões desafetadas e remanescente, antes da configuração atual, de 2016 (Tabela 5). Em relação ao Desflorestamento Acumulado para 2014 (FLONA: 285,50 km²; APA: 834,11 km²; PARNA: 224,37 km²), nota-se que o mesmo é, aproximadamente, 3 vezes maior na APA do que na FLONA e no PARNA, o que comprova a eficiência na estratégia dos posseiros ao usar o desmatamento como forma de pressão para redução da UC.

Tabela 5 - Distribuição de uso por áreas desafetadas ou mantidas

\begin{tabular}{l|l|l|l}
\hline \multicolumn{2}{c|}{ APA (km $\mathbf{~}^{\mathbf{2}}$} & $\begin{array}{l}\text { PARNA } \\
\mathbf{( k m}^{\mathbf{2}}\end{array}$ & Remanescente $\left.\mathbf{( k m}^{\mathbf{2}}\right)$ \\
\hline Área Não Observada & 62,85 & 3,34 & 15,00 \\
Desflorestamento 2014 & 43,59 & 0,90 & 4,74 \\
Floresta & $2.145,33$ & $4.089,60$ & $5.287,70$ \\
Hidrografia & 2,07 & 1,21 & 1,49 \\
Mineração & 0,74 & - & 1,14 \\
Não Floresta & 1,86 & 55,79 & 3,35 \\
Outros & 0,89 & 0,28 & 0,84 \\
Pasto & 632,36 & 135,50 & 154,70 \\
Vegetação Secundária & 157,42 & 87,97 & 124,92 \\
\hline Total Geral & 3047,09 & 4374,58 & 5593,88 \\
\hline
\end{tabular}

Para todas as áreas, a classe com maior percentual dentro do Desmatamento Acumulado é Pasto (FLONA: 54,19\%; APA: 75,81\%; PARNA: 60,39\%), sendo que esse percentual é maior na área do PARNA, uma área de proteção integral, do que na FLONA, uma área de uso sustentável.

Outra informação importante diz respeito à concentração de áreas de Pasto e Mineração dentro da divisão. Como era esperado, as áreas de Pasto em 2014 estão concentradas dentro dos limites que viriam a se tornar APA, representando $68,5 \%$ do total da classe. O que confirma a motivação por pretensões fundiárias de pecuaristas, para a mudança. Em relação à Mineração, no entanto, a maior parte $(60,64 \%)$ se concentra na área que permaneceu como Flona, o que pode ser justificado pela atividade não envolver grandes empresários com poder de influência suficiente, ou também pelo tamanho reduzido que as áreas possuem.

Observando o mapa 4 é possível notar que algumas áreas dos novos limites da Flona, Apa e Parna foram definidas em conformidade exata para incluir polígonos de desmatamento que já existiam. Essa situação é preocupante, pois indica que a legitimação da posse da terra e permanência das atividades na área, foram os principais critérios utilizados para a mudança dos limites, ignorando outros aspectos importantes, como homogeneidade da região, benefício social as populações tradicionais, impacto ecológico sobre fauna e flora locais e, principalmente, a precedência para invasões e grilagens causadas pela remissão de culpabilidade. 
Mapa 4 - Distribuição da Cobertura e Uso do Solo de acordo com a nova configuração das Unidades de Conservação (2014)

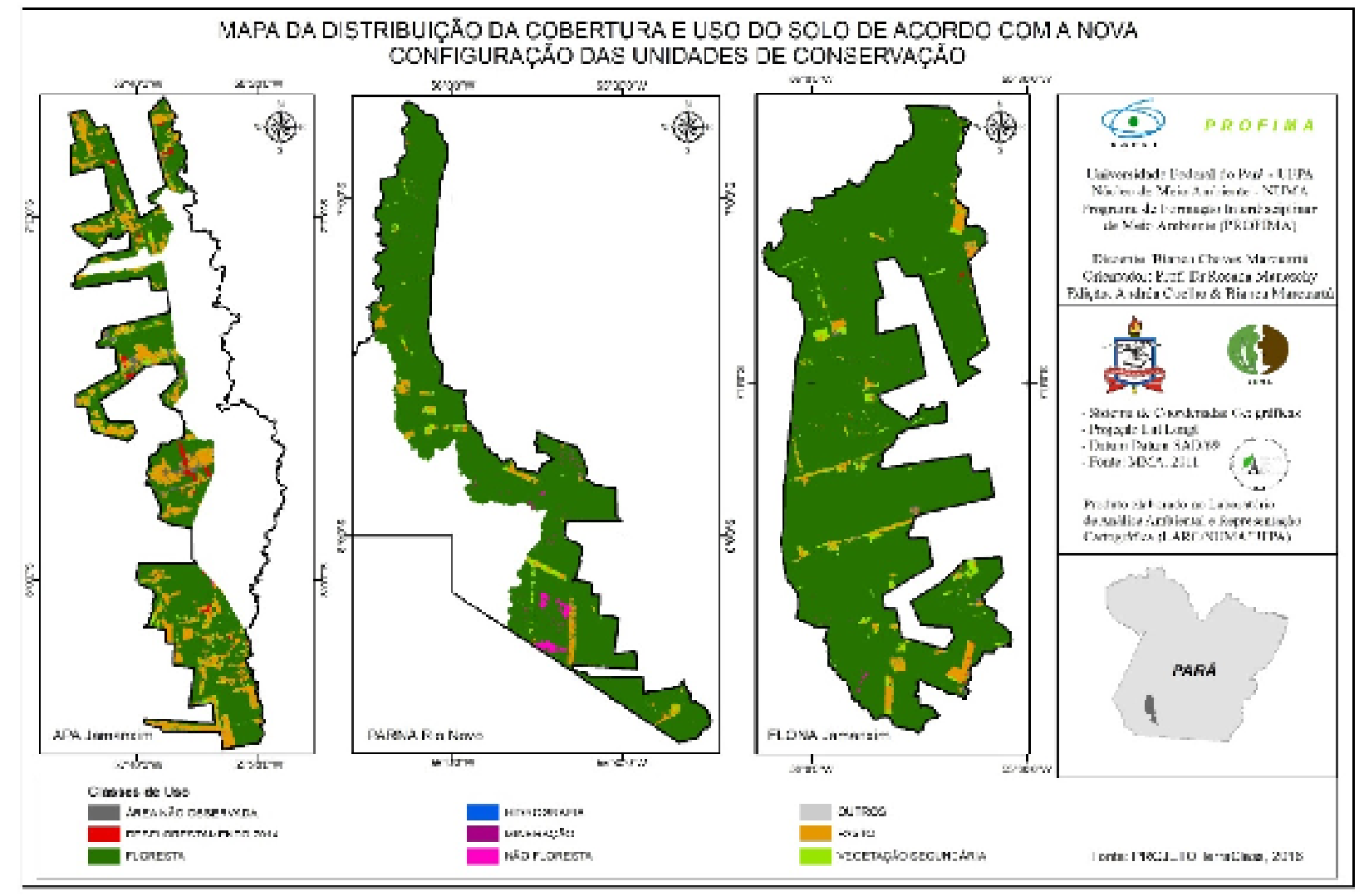

Fonte: Coelho; Marcuartú, 2017

\section{CONCLUSÕES}

O desmatamento na Amazônia vem sendo constantemente justificado pela necessidade do desenvolvimento econômico. Esse processo tem se dado pela demanda por novas terras produtivas, implantação de infraestrutura para log ística de transporte, ou para incremento da matriz energética que visa suprir o consumo e expansão das atividades industriais e serviços nas demais regiões do país, com destaque para a Sudeste. Historicamente, foi construída uma noção de que a apropriação de terras e desrespeito à legislação ambiental pode ser justificada em nome do crescimento econômico e produtividade, impulsionada por diversas atividades ao longo dos anos.

No entanto, as regiões que mais sofrem com a infalível perda da vegetação não usufruem dos supostos benefícios advindos das atividades econômicas e infraestruturas implantadas. O Pará e, particularmente, a região do Tapajós onde grande parte da população vive na linha da pobreza - as pessoas permanecem dentro das áreas mais desfavorecidas do país, revelando que a riqueza gerada é destinada para fora do estado, restando apenas os ônus ambiental e social. Essa situação é ilustrada pela ocupação da Flona Jamanxim, dominada pela presença de áreas de pasto instaladas em grandes propriedades, caracterizada por uma exploração predatória que busca constantemente novas áreas e abandona as antigas. 
Compreender essa dinâmica de uso subsidia o desenvolvimento de políticas públicas para a Amazônia que considerem as peculiaridades do território e suas múltiplas aptidões, bem como que articulem o uso de instrumentos econômicos e de regularização ambiental e fundiária. Essas estratégias devem ser sempre acompanhadas de consistência na aplicação e fiscalização pois, muitas vezes, instrumentos de controle territorial com excelente embasamento e critérios técnicos são ignorados em nome de medidas paliativas e para atender a interesses de grupos específicos.

A situação da FLONA Jamanxim é um reflexo em menor escala de um processo que se repete em toda a região amazônica: a fragilidade do SNUC frente a crises políticas e interesses econômicos sobre suas potencialidades energéticas, minerais e agropecuárias, a exemplo do que ocorre na região do Tapajós, que passa por um processo de (re)ordenamento territorial com o objetivo de viabilizar a instalação de grandes obras de infraestrutura, como o complexo de Aproveitamento Hidrelétrico composto por sete usinas ${ }^{6}$ - que levaram à alteração dos limites de cinco UCs ${ }^{7}$ em 2012; a construção de quatro Estações de Transbordo de Carga $(\mathrm{ETC})^{8}$, no município de Itaituba e Rurópolis; término do asfaltamento do trecho paraense da Rodovia BR-163 e a construção de uma ferrovia que ligará Lucas do Rio Verde/MT a Itaituba/PA, obras que consolidarão a conexão da região com o restante do país e com os principais mercados consumidores do planeta.

Assim, sugere-se a continuação dos estudos para todo o Mosaico de Unidades de Conservação criado no Plano BR-163 Sustentável, a fim de contribuir para os debates acerca da necessidade de garantir a integridade desse que é um dos maiores mosaicos de áreas protegidas de toda a região amazônica.

\section{REFERÊNCIAS}

ARAÚJO, E.; BARRETO, P.; BAIMA, S.; GOMES, M. Unidades de conservação mais desmatadas da Amazônia Legal 2012- 2015. Belém: Imazon, 2017.

BECKER, B. K. A Amazônia nos Cenários para o Planejamento Ambiental. In: Brasil Os Ecossistemas Brasileiros e os Principais Macrovetores de Desenvolvimento. Brasilia: MMA, 1995.

BENATTI, J. H. Ordenamento territorial local e proteção ambiental: aspectos legais e constitucionais do zoneamento ecológico econômico. Meio Ambiente - Grandes Eventos. Brasília: ESMPU, 2004. p. 273-286. v. 1.

BRASIL. Ministério do Meio Ambiente. SNUC - Sistema Nacional de Unidades de Conservação da Natureza: Lei n. 9.985, de 18 de julho de 2000.

BRASIL. Decreto n. 4.340, de 22 de agosto de 2002.

BRASIL. Política Nacional da Agricultura Familiar e Empreendimentos Familiares Rurais: Lei n. 11.326, de 24 de julho de 2006.

BRASIL. Instituto Chico Mendes de Conservação da Biodiversidade. Plano de Manejo da Floresta Nacional do Jamanxim. Curitiba: MMA, 2010. v. 1.

\footnotetext{
${ }^{6}$ AHE São Luis do Tapajós, AHE Jatobá, AHE Chacorão, AHE Cachoeira do Caí, AHE Jamanxim, AHE Cachoeira dos Patos e AHE Jardim do Ouro.

${ }^{7}$ PARN A Amazônia, FLONA Itaituba I, FLONA Itaituba II, FLONA do Crepori, APA do Tapajós.

${ }^{8}$ ETC Itaituba (CIANPORT), ETC Miritituba, ETC HBSA Tapajós e ETC Cargill.

Estudos Geográficos, Rio Claro, 15(2): p-p, ju 1./dez. 2017 (ISSN 1678-698X)

http://www.periodicos.rc.biblioteca.unesp.br/index.php/estgeo
} 
BRASIL. Instituto Chico Mendes de Conservação da Biodiversidade. Estudo Técnico de Revisão dos limites da Floresta Nacional do Jamanxim - Relatório final. Brasília: MMA, 2009

BRASIL. Instituto Nacional de Pesquisas Espaciais. Monitoramento da Floresta Amazônica

Brasileira por Satélite, banco de dados PRODES. 2015. Disponível em: <http://www. obt.inpe.br/prodes/index.html>. Acesso em: 24 mar. 2017.

CANTO, O. Conflito socioambiental e (re) organização territorial: mineradora Alcoa e comunidades ribeirinhas do Projeto Agroextrativista Juruti Velho, município de Juruti-Pará-Amazônia-Brasil. 2012. 269 f. Tese de Doutorado em Desenvolvimento Agrário apresentada à Universidade Federal do Rio Grande do Sul (UFRGS- Porto Alegre, Brasil).

CASTRO, E.; MONTEIRO, R.; CASTRO, C. P. Atores e relações sociais em novas fronteiras na Amazônia e relações sociais em novas fronteiras na Amazônia. Banco Mundial: Relatório de Pesquisa, Brasília. 2002.

CASTRO, E.; MONTEIRO, R.; CASTRO, C. P. Dinâmica de atores, uso da terra e desmatamento na Rodovia Cuiabá- Santarém. Paper do NAEA, Belém, n. 179. 2004

FERREIRA, L. V.; VENTICINQUE, E.; ALMEIDA, S. O desmatamento na Amazônia e a importância das áreas protegidas. Estudos Avançados, São Paulo, v.19, n. 53, p.157-166, 2005.

FONSECA, M.; LAMAS, I.; KASECKER, T. O Papel das Unidades de Conservação. Scientific American Brasil, 2010, ed. Especial, n. 39.

MARTINS, $H$. et al. Desmatamento em Áreas Protegidas Reduzidas na Amazônia. Boletim. Belém: Imazon, 2014

MEDEIROS, R.; YOUNG; C. E. F.; PAVESE, H. B.; ARAÚJO, F.F.S. Contribuição das unidades de conservação brasileiras para a economia nacional. Sumário Executivo. Brasília: UNEP-WCMC, 2011.44p.

ROCHA, G. M.; CANTO, O. Zoneamento ecológico-econômico da área de influência da rodovia BR-163 (Cuiabá-Santarém): diagnostico do meio socioeconômico, jurídico e arqueológico. Estrutura Espacial e Formação Territorial dos Municípios. Belém: Embrapa da Amazônia Oriental, 2007. v. 1.

SOARES-FILHO, B. et al. Role of Brazilian Amazon protected areas in climate change mitigation. Proceedings of the National Academy of Sciences of the United States of America. Nova York, v.107, n.24, p.10821-10826, 2010.

SOUZA, R. Conflitos Ambientais em Unidades de Conservação: Dilemas na Gestão da APA Nhamundá. In: CONGRESSO BRASILEIRO DE GEÓGRAFOS VII. Vitória. Anais: AGB. 2014

VALLEJO, L. R. Unidade de Conservação: Uma Discussão Teórica á Luz dos Conceitos de Território e Políticas Públicas. Geographia, Niterói, v. 4, n. 8, p. 57-78. 2002. http://www.uff.br/geographia/ojs/index.php/geographia/article/view/88. Acesso em: 04 mai. 2017. 
VENTURIERI, A. (Org.). Zoneamento ecológico-econômico da área de influência da rodovia BR 163 (Cuiabá-Santarém). v. 1. Belém: Embrapa Amazônia Oriental, 2008. 